\title{
A Cross Sectional Study Of The Prevalence Of Depression Among The Male Post-Graduate Medical Students Of Gauhati Medical College And Hospital, India
}

\author{
Dr. Heemanshu Shekhar Gogoi, Post-graduate trainee \\ Department of Physiology, Gauhati Medical College and Hospital, India.
}

doi: 10.19044/esj.2016.v12n14p262 URL:http://dx.doi.org/10.19044/esj.2016.v12n14p262

\begin{abstract}
Background: Depression is defined according to the WHO as a common mental disorder, characterized by sadness, loss of interest or pleasure, feelings of guilt or low self-worth, disturbed sleep or appetite, feelings of tiredness, and poor concentration. One-fourth to one-third of the post-graduate medical trainees and residents develop clinical depression at some point in their training period although much higher rates were reported in some other studies. Objective: To evaluate the prevalence of depression along with its different degrees among the male post-graduate students in Gauhati Medical College and Hospital. Material and method: This study was performed on 120 male post-graduate medical students according to inclusion and exclusion criterias. The 'Hamilton Depression Rating Scale (HAM-D)' was used for evaluating depression. Result: The prevalence of depression among the male post-graduate medical students is 37\% (mild depression-16\%, moderate depression-14\%, severe depression-7\% and lastly very severe depression -0\%) in Gauhati Medical College and Hospital. Conclusion: This study shows that the male post-graduate medical students are suffering from psychological distress which is leading them into depression. This issue should be properly addressed because of its possible impact on quality of health care services in teaching hospitals and on training outcome.
\end{abstract}

Keywords: Depression, Prevalence, Hamilton Depression Rating Scale, Psychological, Post-graduate students

\section{Introduction}

The world today is full of hardships, toil and labour and immense competition in each and every fields. This eventually leads a person to fall 
victimised to certain psychological and psychiatric deficits. Depression is one of such an unwelcoming event.

Depression is defined according to the WHO as a common mental disorder, characterized by sadness, loss of interest or pleasure, feelings of guilt or low self-worth, disturbed sleep or appetite, feelings of tiredness, and poor concentration (Marina Marcus et al, 2014). The term depression has been used variously to describe an emotional state, a syndrome, and a group of specific diseases. When seen as a part of a syndrome or disorder, depression has autonomic, visceral, emotional, perceptual, cognitive, and behavioural manifestations. As a non-pathological ubiquitous mood state lasting from hours to days, but sometimes longer, feeling of depressive are synonymous with feeling sad, blue, down in the dumps, unhappy and miserable. Depressed mood is common and appropriate following a disappointment or loss (Benjamin J. Sadock et al, 2000). According to WHO, Depression has been ranked fourth in the list of most urgent health problem World wide (Akiskal HS et al, 2004).

Health is not merely an absence of disease or infirmity but is a state of physical, mental and social well-being. Mental health refers to a broad array of activities directly or indirectly related to the mental well-being component included in the World Health Organization's definition of Health. Mental Health problems are a major public health concern due to their high prevalence rates, difficulties related with identification, treatment and their tendencies to become chronic. One of the mental disorders which have a particularly high prevalence is depression (Ramesh K et al, 2014). According to World Health Organization (WHO), depressive disorders are the fourth leading health problem in the world. Bartlett pointed out there are immense empirical support for the belief that anxiety and depression impacts adversely on physiological and mental health (Bartlett D et al, 1998). A student of medical course has to read many hours a day routinely to understand vast field of study. Family and society has very high expectations from them (K. Modi et al, 2013). Studies, related to anxiety and depression among students of such professional courses, have been reported from abroad, but such data from India is scarce. Medical school is recognized as a stressful environment that often exerts a negative effect on the academic performance, physical health and psychological well-being of the student (Khan MS et al, 2006). Among medical students, academic stressors include the volume of material to be learned, academic performance and evaluation (examination and continuous assessment). Academically less successful students reported somewhat higher levels of depressive ideation and symptomatology (Stewart SM et al, 1995). The potential negative effects of emotional distress on medical students include impairment of functioning in classroom performance and clinical practice, stress-induced 
disorders and deteriorating performance (Malathi A et al, 1999), (Bramness JA et al, 1991). Among all physicians, resident doctors have an exceptional position. Residency training is a stressful course with frequent encounters with severely ill patients, lengthy work hours, persistent threat of being sued by patients, and a need to study regularly to keep up to date. These factors make them vulnerable to depression (Sadeghi M et al, 2007).

One-fourth to one-third of the post-graduate medical trainees and residents develop clinical depression at some point in their training period although much higher rates were reported in some other studies (Katz ED et al, 2006). Variable prevalence rates for depression among medical students and residents have been reported ranging from $2 \%$ to $35 \%$, with the highest rates among residents (Katz ED et al, 2006), (Goebert D et al, 2009). In a study on depression and its associated risk factors in medical and surgical post graduate trainees at a teaching hospital overall frequency of depression was 59.88\% which is higher than the Washington study that shows frequency of depression as 12\% among emergency medicine residents in 2003 to 2004 (Katz ED et al, 2006), (Yousuf A et al, 2011). In a multi-centre study to find out the prevalence of depression among post-graduate medical trainees, twofifth of post-graduate medical trainees were found to be suffering from mild to moderate depression (Zaman S et al, 2014).

\section{Aims and objectives}

1. To access and evaluate the prevalence of depression among the male post-graduate students in Gauhati Medical College and Hospital.

2. To access and evaluate the prevalence of degree of depression among the male post-graduate students who are suffering from depression in Gauhati Medical College and Hospital.

\section{Materials and methods}

This study was carried out in Gauhati Medical College and Hospital, Guwahati for a duration of nine months from $1^{\text {st }}$ of July, 2015 to $31^{\text {st }}$ of March, 2016.

i. It was a cross-sectional population based study.

ii. Simple random sampling and voluntary participation of the subjects.

iii. The written and informed consent of the subjects was obtained prior to collection of data.

iv. Strict confidentiality was maintained regarding the subjects and their datas.

v. Background information of all the subjects about their age, family, marital status as well as was their various academic aspects and educational qualifications, extracurricular and re-creational activities were collected using a detailed questionnaire. 


\section{Inclusion criteria}

i. Only male post-graduate medical students of Gauhati Medical College were selected.

ii. Students who had spent more than six months in the college were included in this study.

iii. Both single and married subjects.

iv. 25 to 40 years of age.

v. No family history of psychiatric or psychological disorders.

vi. Students neither diagnosed nor treated for any psychiatric or psychological disorders.

vii. Students without any physical illness at the time of survey .

\section{Exclusion criteria}

i. All female post-graduate medical students.

ii. Male post-graduate medical students of other medical colleges except Gauhati Medical College and Hospital.

iii. Students who had spent less than six months in college were excluded from this study.

iv. Less than 25 or more than 40 years of age.

v. Family history of psychiatric or psychological disorders

vi. Students who were already diagnosed and treated for any psychiatric or psychological disorders.

vii. Students who reported presence of a physical illness at the time of survey.

This cross-sectional study was done among a total of 120 subjects, based on inclusion and exclusion criterias who were male post-graduate medical students of the different departments of Gauhati Medical College and Hospital which is located in the Guwahati city of Assam which is a state in the north-eastern region of India. This study was conducted in the male post-graduate medical students' hostels as well as in the different departments of the college. Strict confidentiality of the subjects as well as their datas were maintained. To access and evaluate the prevalence of depression as well as its various degrees the 'Hamilton Depression Rating Scale (HAM-D)' was used.

The Hamilton Depression Rating Scale (HAM-D) has proven useful for many years as a way of determining a patient's level of depression before, during, and after treatment. It should be administered by a clinician experienced in working with psychiatric patients. Although the HAM-D form lists 21 items, the scoring is based on the first 17. It generally takes 1520 minutes to complete the interview and score the results. Eight items are scored on a 5-point scale, ranging from $0=$ not present to $4=$ severe. Nine are scored from 0-2 (Hedlug et al, 1979). 
A good rapport was established between the investigator and respondent. The instructions of each part of the questionnaires were adequately explained and care was taken to ensure that they understood the questionnaire. Each participant was requested to respond to each item in the questionnaire freely and frankly without any hesitation. Each participant was asked to clarify for understanding before they attempted to respond.

\section{HAM-D scoring instructions}

Sum the scores from the first 17 items.

$0-7=$ Normal.

8-13 = Mild Depression.

14-18 = Moderate Depression.

19-22 = Severe Depression.

$\geq 23=$ Very Severe Depression.

\section{Results}

In this study the following results were found.

Out of 120 male post-graduate medical students 44 subjects were found to have depression and the rest 76 students were normal as depression was not found in them. So, the prevalence of the subjects suffering from depression out of the total 120 subjects is found to be $37 \%$ and the prevalence of the normal subjects having no depression is found to be $63 \%$. Now, categorically according to the degree of depression, 19 subjects out of 120 subjects were found to be suffering from mild depression, so the prevalence of mild depression out of the total number of subjects is $16 \%$. Similarly, the prevalence of moderate depression is $14 \%$ (17 moderately depressed subjects among 120 subjects), the prevalence of severe depression is $7 \%$ (8 severely depressed subjects among 120 subjects) and lastly the prevalence of very severe depression among the male post-graduate medical students in Gauhati Medical College is 0\% (not even a single severely depressed subject was found among the studied subjects) (see Table-1 and Fig-1).

Table-1: This table shows the prevalence of depression among the male post-graduate students in Gauhati Medical College and Hospital.

\begin{tabular}{|c|c|c|c|}
\hline S. No. & Degree of depression & $\begin{array}{c}\text { No. of subjects out of } 120 \\
\text { subjects }\end{array}$ & $\begin{array}{c}\text { Percentage (\%) of } \\
\text { prevalence }\end{array}$ \\
\hline 1. & No depression & 76 & $63 \%$ \\
\hline 2. & Mild depression & 19 & $16 \%$ \\
\hline 3. & Moderate depression & 17 & $14 \%$ \\
\hline 4. & Severe depression & 8 & $7 \%$ \\
\hline 5. & Very severe depression & 0 & $0 \%$ \\
\hline
\end{tabular}




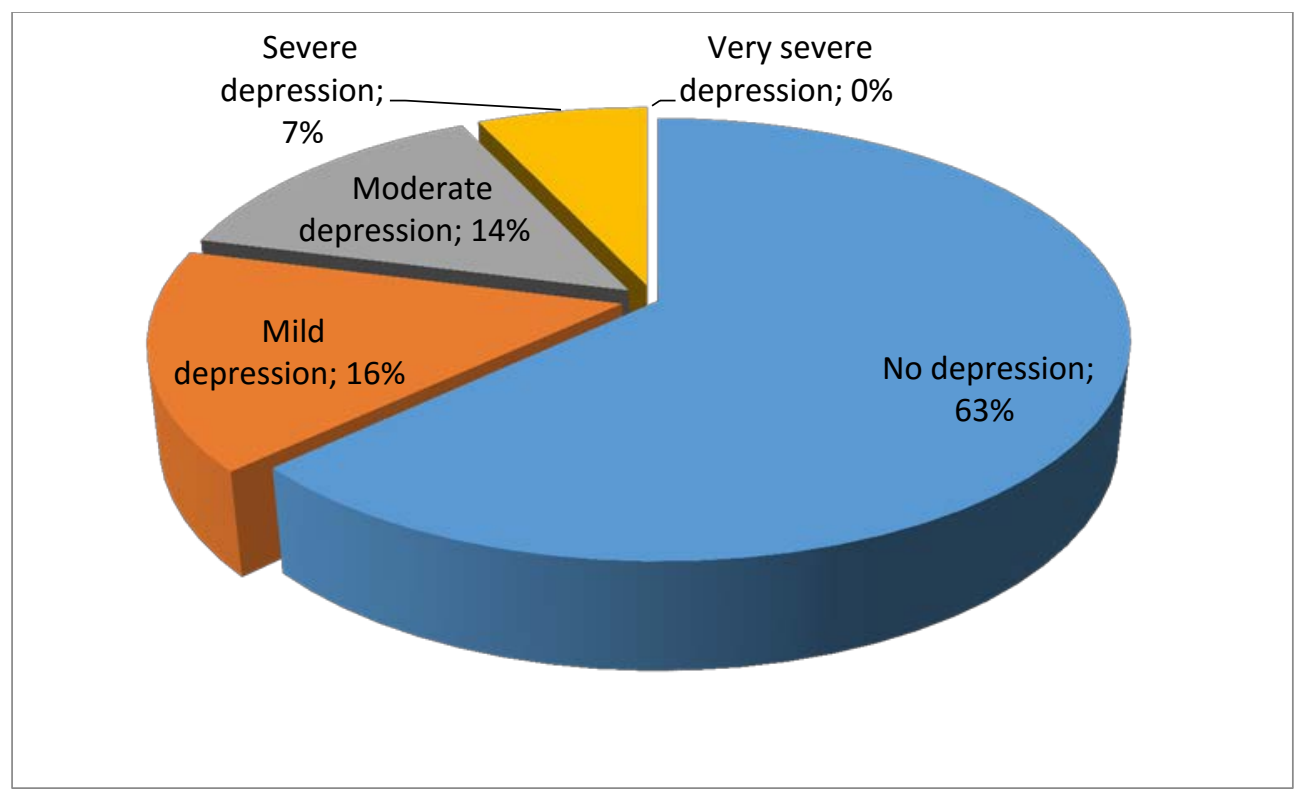

Fig-1: This figure shows the prevalence of depression among the male post-graduate medical students in Gauhati Medical College and Hospital.

Now, among only the 44 male post-graduate medical students who are found to be suffering from depression, the prevalence of the different degrees of depression are as follows -

19 subjects out of 44 depressed subjects were found to be suffering from mild depression, so the prevalence of mild depression out of the total number of subjects who are suffering from depression is $43 \%$. Similarly, the prevalence of moderate depression is 39\% (17 moderately depressed subjects among 44 subjects), the prevalence of severe depression is $18 \%$ (8 severely depressed subjects among 44 subjects) and lastly the prevalence of very severe depression among the 44 depressed male post-graduate medical students in Gauhati Medical College is 0\% (not even a single severely depressed subject was found among the studied subjects suffering from depression) (see Table-2 and Fig-2).

Table-2 : This table shows the prevalence of degree of depression among the male postgraduate medical students who are suffering from depression in Gauhati Medical College and Hospital.

\begin{tabular}{|c|c|c|c|}
\hline S. No & Degree of depression & $\begin{array}{c}\text { No. of subjects out of 44 } \\
\text { subjects suffering from } \\
\text { depression }\end{array}$ & $\begin{array}{c}\text { Percentage (\%) of } \\
\text { prevalence }\end{array}$ \\
\hline 1. & Mild depression & 19 & $43 \%$ \\
\hline 2. & Moderate depression & 17 & $39 \%$ \\
\hline 3. & Severe depression & 8 & $18 \%$ \\
\hline 4. & Very severe depression & 0 & $0 \%$ \\
\hline
\end{tabular}




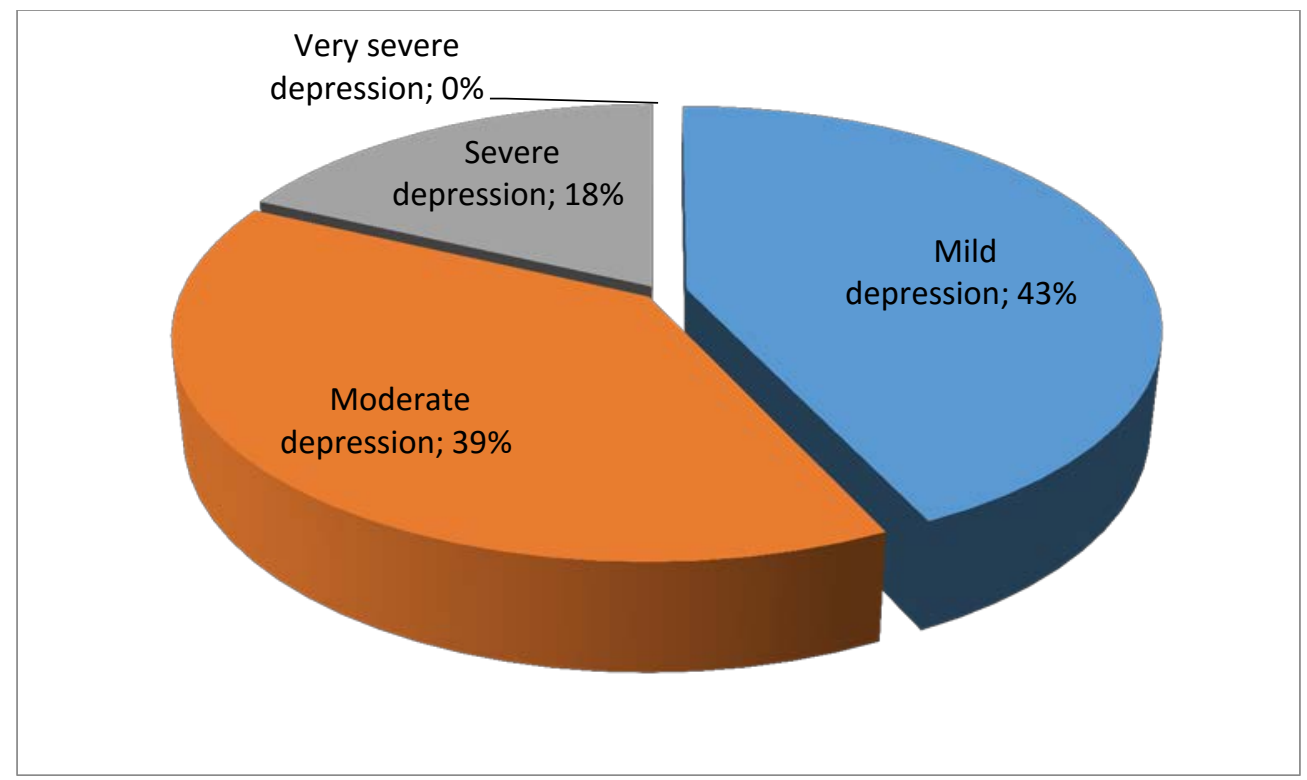

Fig-2: This figure shows the prevalence of degree of depression among the male postgraduate medical students who are suffering from depression in Gauhati Medical College and Hospital.

\section{Discussion}

Residency involves stress to both the personal and professional lives of residents. It demands long hours within the training environment, as well as dedication outside of it. Residents must cope with clinical, academic, physical, and social demands while working up to 80 hours a week (Katz ED et al, 2006) Stress and depression can both be caused by life events and medical conditions. The one difference is that stress can be caused by pleasant events such as a promotion or marriage, while depression is associated with unwelcome events like financial difficulties or death. The struggle consists of demands on time, financial pressures, parental pressure and conflicts, interpersonal conflicts, managing freedom, peer and academic pressure and the transitional period to a new academic environment. All of these factors combined can cause emotional disturbances.

Depression and anxiety levels in the community are considered as specific indicators for mental status of a person. Various studies have documented stress among medical students (John A ET AL, 1997). Depression and anxiety are commonest mental illnesses especially in adolescents. Among medical students, academic stressors include the volume of material to be learned, academic performance and evaluation (examination and continuous assessment). Academically less successful students reported somewhat higher levels of depressive ideation and symptomatology (Stewart SM et al, 1995). The potential negative effects of emotional distress on 
medical students include impairment of functioning in classroom performance and clinical practice, stress-induced disorders and deteriorating performance (Malathi A et al, 1999), (Bramness JA et al, 1991). In a study done by Zaman $\mathrm{S}$ et al on the prevalence of depression among post-graduate medical trainees in 2014 in three post-graduate medical teaching institutes in Dhaka a total of 100 post-graduate medical trainees were given the questionnaire by person to person contact or by email. Among them 53 students filled up the form properly and sent it back within a given time. So, the response rate in their survey was 53\%. In their study also the severity of depression was assessed by Hamilton Rating Scale for Depression and they found that $39.6 \%$ of the respondents had mild depression. Out of which 80.9\% had mild depression and $19.1 \%$ had moderate depression. None had severe or very severe depression (see figure 3). In this current study, 37\% of the studied population had depression, which is slightly lower as compared to the study done by Zaman $\mathrm{S}$ et al and much lower to a similar study done by Yousuf $\mathrm{A}$ et al in 2011 but the depression is about three times more frequent as compared to an another study done in the United States by Katz ED et al in 2006.

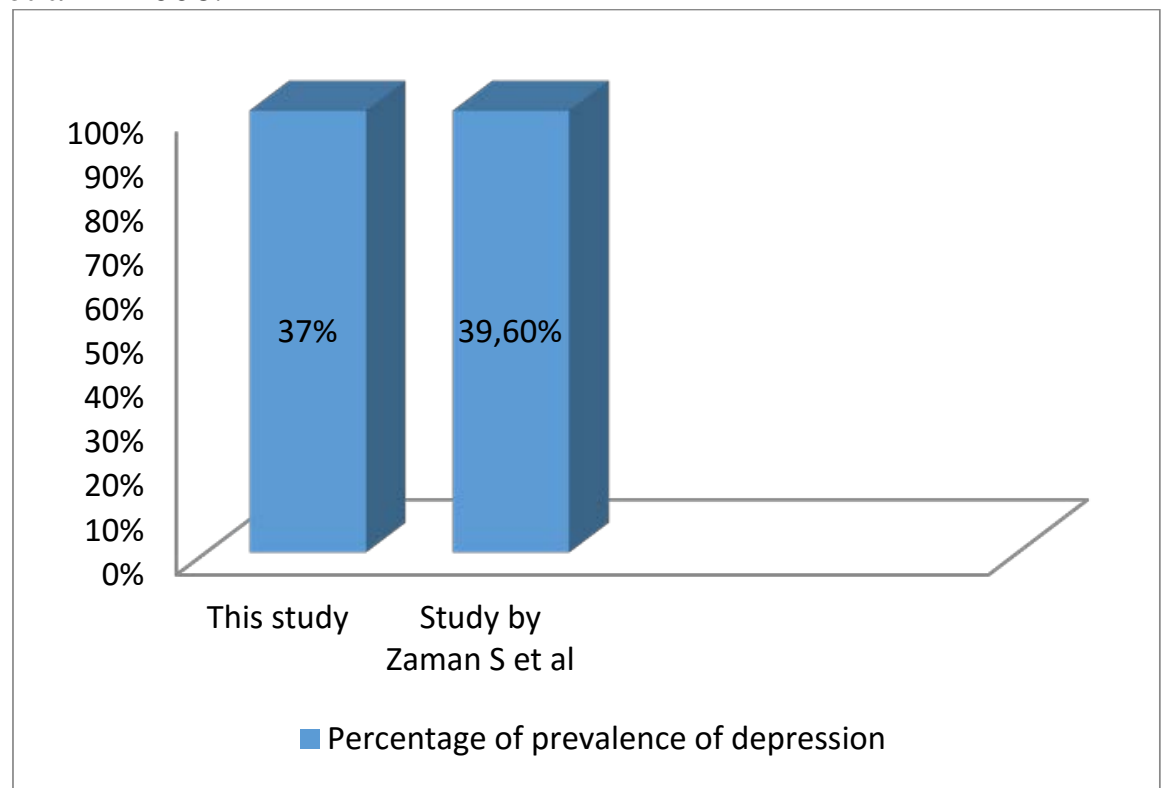

Fig-3: This figure shows the percentage of prevalence of depression in our study along with the one done by Zaman S et al in 2014. In both of these studies Hamilton Depression Rating Scale was used to assess the prevalence of depression.

Medical students constitute a vulnerable group that has a high prevalence of psychiatric morbidity comprising of anxiety and depression . Amongst medical students, stress has been reported to be due to academic demands, exams, inability to cope, helplessness, increased psychological 
pressure, mental tension and too much work load (Shaikh BT et al, 2004). Several studies have reported high rates of psychological morbidity amongst medical students using various instruments (Dahlin $\mathrm{ME}$ et al, 2007), (Guthrie E et al, 1998). Previous studies in Pakistan have shown a higher prevalence of anxiety and depression in medical students (Khan MS et al, 2006), (Inam SNB et al, 2003). Such findings are most likely related to academic, financial and social demands that college environments place on students at a time when they are also involved in issues related to life style and careers. Retrieving knowledge about psychiatric morbidity is important as it can help in implementing preventive mental health programmes.

Men generally have a hard time dealing with the stigma of depression. They are more likely to deal with their symptoms with by drinking alcohol or abusing drugs, and/or pursue other risky behaviour. Many men avoid talking about depressed feelings to friends or family. Male depression often goes undiagnosed. Men with depression often aren't diagnosed, for several reasons. Possible reasons behind male depression includes failure to recognize depression, fatigue, irritability, neglecting signs and symptoms, employment, lack of purpose in life, substance addiction and emphasis on self-control. So men should practice healthy coping skills rather than automatically turning to alcohol. So they need to set realistic goals and prioritize tasks. They should seek emotional support from friends and family members. Understanding how men in our society are brought up to behave is particularly important in identifying and treating their depression. Depression in men often can be traced to cultural expectations. Men are supposed to be successful. They should rein in their emotions. They must be in control. These cultural expectations can mask some of the true symptoms of depression.

Women were found to have a significantly higher rate of probable major depression compared with men for both students and residents $(\mathrm{P}<$ 0.001) in a multi institutional study by Goebert D et al in 2009. Western data suggest that females experience high levels of stress as compared to males (Ali BS et al, 1998). Several studies have reported significant distress among medical students (Clark DC et al, 1988), (Lloyd C et al, 1984), (Vitaliomo PP et al, 1988). On the other hand some studies have found little or no evidence of stress among medical students (All Bet al, 1998). However some studies consider parental (Fadem B et al, 1995) and social support (Rospenda et al, 1994) as a definitive variable, which may influence the academic performance and mental status of medical students. An Indian study had identified academic sources as important causes of perceived stress in undergraduate medical students and hence major category of 
concern (Supe AN et al, 1998). A Boston study on first and second year medical students reported lowest family income as a important contributor to depression (13.9\%) and high trait anxiety symptoms (77.3\%) (Mancevska S et al, 2008).

Depression is well known to initiate a thought of worthlessness/ hopelessness/ helplessness and can promote suicidal ideation. A recently conducted Chinese study reported $7.5 \%$ suicidal ideation among medical students. This figure can go high up to $30 \%$ in depressed students (Sobowale $\mathrm{K}$ et al, 2014). Studies have also reported suicidal ideation among medical students. A nation-wide prospective study from Norway (Tyssen $\mathrm{R}$ et al, 2001) revealed prevalence of suicidal thoughts in $14 \%$. The life time prevalence was 43\%, $8 \%$ had planned suicide and $1.4 \%$ attempted suicide. Depression was more common among married, male trainees in a study on prevalence of depression among post-graduate medical trainees ( Zaman S et al, 2014). A medical student has to read many hours a day routinely to understand vast field of health care. Family and society has very high expectations from them. The study lends weight to our belief that the medical students have considerable amount of perceived stress or mental pressure. The stress levels likely to be higher during exam periods as (Saipanish $\mathrm{R}$ et al, 2003) reported in several studies. Even though many students felt the need for counselling sometime in last year none of them sought any professional help. Similar lack of use of mental health counselling services are also reported from (Givens JL et al, 2002) developed countries. Patients with major depression also often display neurocognition deficits consisting with frontal lobe dysfunction, though the deficits are generally not as severe as those seen in schizophrenia (Rogers MA et al, 2004).

Mental health of medical students has attracted attention of researchers since last few decades. This is because medical students reported higher level of anxiety and depression compared to general population and peers of same age groups (Dyrbye LN et al, 2006). Medical students from private medical college exhibit more depression than those attending public medical schools (Saravanan C et al, 2014). A study in U.S. medical students estimated approximately $10 \%$ prevalence of suicidal ideation during medical program (Dyrbye LN et al, 2008). Students in extreme stress or depression need serious attention (Vaz RF et al, 1998), otherwise inability to cope successfully with the enormous stress of education may lead to a cascade of consequences at both personal and professional levels (John A et al, 1997). Anxiety and depression has a very high cost to individual and society, including medical school dropout (Clark DC et al, 1988), (Zoccolillo $\mathrm{M}$ et al, 1988), suicide (Pepitone A et al, 1981), 
degeneration of relationship (Clark El et al, 1986), marital problems and impaired ability to work effectively (Valko R et al, 1975).

\section{Conclusion}

This study has shown that the prevalence of depression among the male post-graduate medical students is $37 \%$ (mild depression is $16 \%$, moderate depression is $14 \%$, severe depression is $7 \%$ and lastly very severe depression is 0\%) in Gauhati Medical College and Hospital. Thus, this study shows that the male post-graduate medical students in a medical institute are suffering from psychological distress which is leading them into depression.

The limitations of this study were small sample size, conductance at single institute and also study results were based on questionnaires pattern so chances of reporting bias can present as students may be reluctant to expose depressive thoughts or suicidal ideations. In addition, limitations of the study also include lack of baseline information concerning mental status of medical students at the time of entrance in the medical school and lack of population based data to support our results and compare our findings with the general population. So the findings can't be generalized. In future, larger, multi-centric studies are needed to find the sources of stress, stressors variation with different factors and associated psychological disturbances in medical students. Also, there is scope for a study regarding depression among the female post-graduate medical students in a single or multiple medical institutes. As minimal literature is there documenting prevalence of depression among post graduate medical students, this study was undertaken with the objective of evaluating the prevalence of depression among male post-graduate medical students in a medical institute. It has been reported that medical students are reluctant to seek appropriate help for mental health problems and view it as a weakness. This issue needs to be addressed and students should be encouraged to seek help along with provision of adequate facilities. Dahan \& Bedos. recommended the implementation of two strategies to help stressed students- (i). decreasing number of stressor and (ii). increasing ability to cope with stress (Dahan $\mathrm{H}$ et al, 2010).

Counseling is identified as a useful tool for reducing the level of depression among medical students by building self-confidence and the capacity to adjust (Velayudhan A et al, 2010). Counselors in each medical institute, who with regular follow-up services, can assist in personal and professional development of students. Screening at the time of entrance and further evaluation of positive cases by a psychiatrist can establish baseline data. Follow-up studies for monitoring prevalence of depression will help in instituting intervention strategies. To conclude, the prompt measures to deal with depression will be likely to result in improved 
well-being of doctors and will result in better quality of care offered to patients. This issue should be properly addressed because of its possible impact on quality of health care services in teaching hospitals and on training outcome. Thus, in this way can we combat and prevent depression as this gives a true hope to make and enrich our lives as well as the lives of others all around the world happy, healthy and beautiful.

\section{Acknowledgement}

I express my deep sense of gratitude to my father Mr. Horen Gogoi and my mother Mrs. Kiron Gogoi for their unending love and support and Dr. (Mrs.) Bonti Bora (Professor \& Head of the Department of Physiology, Gauhati Medical College and Hospital) as without her support this project might not have been successful. A very special thanks to Dr. Kishore K Deepak sir (Professor and Head of the Department of Physiology of All India Institute of Medical Sciences, New Delhi, India) for reviewing my article. Thank you to all the participants of this study for giving me their valuable time and patience for my work. Thank you everyone for everything.

\section{References:}

Akiskal HS. Mood Disorder. Historical Introduction \& Conceptual overview. In: Saddock BJ, Saddock VA(eds), Kaplan \& Saddock’s Comprehensive Textbook of Psychiatry, 8/e, Lippicott, William \& Wilkins, Philadelphia 2004;1:1559.

Ali BS, Amanullah S. A comparative review of two screening instruments: the Aga Khan University anxiety and depression scale and the self reporting questionnaire. J Pak Med Assoc 1998:48:79-82.

All B. Validation of an indigenous screening questionnaire for anxiety and depression in an urban squatter settlement of Karachi, J Coil Physician Surg 1998; 8:207-10.

Bartlett D. Stress Perspectives and processes. Buckingham. Philadelphia: Open University Press; 1998.

Benjamin J. Sadock, M.D., Virginia A. Sadock, M.D. Kaplan \& Sadock’s Comprehensive Textbook of Psychiatry. Volume one. Seventh edition. 2000. Lippincott Williams \& Wilkins.Pg. no. 813.

Bramness JA, Fixdal TC. Vaglum P. Effect of medical school stress on the mental health of medical students in early and late clinical curriculum. Acta Psychiatr Scand 1991; 84:340-5.

Clark DC, Zeellow PB. Vicissitudes of depressed mood during four years of medical school. JAMA 1988:260: 2521-8.

Clark El, Reicker PP. Gender Differences in relationships and stress of medical and law students J Med Edu 1986:61 :32-40. 
Dahan H, Bedos C; A typology of dental students according to their experience of stress: A qualitative study. J Dent Educ., 2010; 74:95- 103. Dahlin ME, Runeson B. Burnout and psychiatric morbidity among medical students entering clinical training: a three year prospective questionnaire and interview-based study. BMC Med Educ 2007; 7: 6.

Dyrbye LN, Thomas MR, Massie FS, Power DV, Eacker A, Harper W et al; Burnout and suicidal ideation among U.S. medical students. Ann Intern Med., 2008; 149:334-41.

Dyrbye LN, Thomas MR, Shanafelt TD; Systematic review of depression, anxiety, and other indicators of psychological distress among US and Canadian medical students. Academic Medicine, 2006; 81:354-73.

Fadem B. Schuchman M, Simring SS, et al. The relationship between parental income and academic performance of medical students. Acad Med 1995;70:1 142-44.

Givens JL, Tjia J. Depressed medical students' use of mental health services and barriers to use. Acad Med. 2002;77:918-21.

Goebert D, Thompson D, Takeshita J, Beach C, Bryson P, Ephgrave K, et al. Depressive symptoms in medical students and residents: a multischool study. Acad Med [serial online] 2009 [cited 2014 Dec 7]; 84 (2): 236-41. Available from:

URL: http://journals.lww.com/academicmedicine/Fulltext/2009/02000/Depressive_ Symptoms_in_Medical_Students_and.34.aspx.

Guthrie E, Black D, Bagalkote H, Shaw C, Campbell M, Creed F. Psychological stress and burnout in medical students: a five-year prospective longitudinal study. J R Soc Med 1998; 91: 237-43.

Hedlug and Vieweg. The Hamilton Rating Scale for Depression. Journal of Operational Psychiatry. 1979; 10(2): 149-165.

Inam SNB, Saqib A, Alam E. Prevalence of anxiety and depression among medical students of private university. J Pak Med Assoc 2003; 53: 44-7.

John A, Towes MD, Jocelyn M, et al. Analysis of stress levels among medical students residents and graduate students at four Canadian school of medicine. Acad Med 1997; 72:997-1002.

K. Modi, D. Kumar. "Anxiety and Depression in Medical Students and its association with Coping Methods adopted by them”.IJRRMS.2013; vol 32:pp 20-22.

Katz ED, Sharp L, Ferguson E. Depression among emergency medicine residents over an academic year. Acad Emerg Med [serial online] 2006 [cited 2014 Dec 7]; 13 (3):284-7. Available from: URL: http: //onlinelibrary.wiley.com/doi/10.1197/j.aem.2005.10.009/pdf.

Khan MS, Mahmood S, Badshah A, Ali SU, Jamal Y. Prevalence of Depression, Anxiety and their associated factors among medical students in 
Karachi, Pakistan. J Pak Med Assoc [serial online] 2006[cited 2014 Dec 7]; 56 (12): 583-6. Available from: URL: http://www.jpma.org.pk/PdfDownload/959.pdf.

Lloyd C, Crartrell NKA. Psychiatric symptoms in medical students. Compr Psychiatry 1984;25:552-65.

Malathi A, Damodaran A, Stress due to exams in medical students- role of yoga. Indian J Physiol Pharmacol 1999 Apr. 43 2]: 218-24.

Mancevska S, Bozinovska L, Tecce J, PluncevikGligoroska J, SivevskaSmilevska E; Depression, anxiety and substance use in medical students in the Republic of Mecedonia. Bratisl Lek Listy.,2008; 109:568-72.

Marina Marcus, M. Taghi Yasamy, Mark van Ommeren, and Dan Chisholm, Shekhar Saxena. World Health Organization. Depression: A Global Public Health Concern. [serial online][cited 2014 Nov 20] Available from: URL: http://www.who.int/mental_health/management/depression/who_paper_depr ession_wfmh_2012.pdf.

Pepitone A. Rockwell F. Rockwell D. et al. Fifty two medical students suicide. Am J Psychiatry 1981; 138:198-201.

Ramesh K, T. Gangadhara Goud Prevalence of Depression among Medical and Engineering students, Bellary, Karnataka, India. International Journal of Scientific Research [serial online] 2014 [cited 2014 Nov 20]; 3 (4). Available from:

URL: http://theglobaljournals.com/ijsr/file.php?val=April_2014_1396617551_cafe 4_187\%20Ramesh\%20K-2.pdf.

Rogers MA, Kasai K, Koji M, et al. (2004) Executive and Prefrontal dysfunction in unipolar depression : a review of neuropsychological and imaging evidence. Neuroscience Research, 50, 1 - 11.

Rospenda, KM. Hepret J. Richmom JA. Effects of social support on medical students performances. Acad Mcd 1994:496-500.

Sadeghi M, Navidi M, Sadeghi AE. Depression among resident doctors in Tehran, Iran. Iran J Psychiatry [serial online] 2007 [cited 2014 Dec 7]; 2: 5052. Available from:

URL: http://ijps.tums.ac.ir/index.php/ijps/article/view/38/37 .

Saipanish R. Stress among medical students in a Thai medical school. Med T each. 2003; 25:502-6.

Saravanan C, Wilks R; Medical students' experience of and reaction to stress: The role of depression and anxiety. The Scientific World Journal 2014; Article ID 737382. http://dx.doi.org/10.1155/2014/737382.

Shaikh BT, Kahloon A, Kazim M, Khalid H, Nawaz K,Khan N, et al. Students, stress and coping strategies: a case of Pakistani medical school. Educ Health (Abingdon) 2004; 17: 346-53. 
Sobowale K, Zhou AN, Fan J, Liu N, Sherer R; Depression and suicidal ideation in medical students in China: a call for wellness curricula. Int J Med Educ., 2014; 5:31-6.

Stewart SM, Betson C, Marshall i, etal. Stress and vulnerability in medical students. Med Edu 1995; 29:119-27.

Supe AN; A study of stress in medical students at Seth GS Medical College. J Postgrad Med., 1998; 44:1-6.

Tyssen R, Vaglum P, Gronvold NT, Ekeberg O. Suicidal ideation among medical students and young physicians: a nationwide and prospective study of prevalence and predictors. J Affective Disord. 2001 Apr;64(1):6979. [PubMed].

Valko R. Clayton P. Depression in the internship. Dis Nerv Syst 1975: 36:26-9.

Vaz RF, Mbajiorgu EF, Acuda SW. A preliminary study of stress levels among first year medical students at the university of Zimbabwe. Cent Afr $\mathrm{j}$ Med 1998:44:214-19.

Velayudhan A, Gayatridevi S, Bhattacharjee RR; Efficacy of behavioural intervention in reducing anxiety and depression among medical students. Ind Psychiatry J., 2010; 19:41-6.

Vitaliomo PP. A biopsychosocial model of medical student distress. J Behav Med 1988;11:311-13.

Yousuf A, Ishaque S, Qudwai W. Depression and its associated risk factors in medical and surgical postgraduate trainees at a teaching hospital: a crosssectional survey from a developing country. J Pak Med Assoc [serial online] 2011 [cited 2014 Dec 11]; 61: 968-72. Available from: http://www.jpma.org.pk/PdfDownload/3013.pdf.

Zaman S, Rahim MA, Khan AH, Habib SH, Rahman NH, Ahsan MS, Afroze SR, Haque HF, Ahmed JU, Ahmed AKMS, Hossain MD, Rahman MR, Musa AKM, Uddin KN. Prevalence of Depression Among PostGraduate Medical Trainees: A Multi-Centre Survey. Birden Medical Journal.2014: 4(1):18-21.

Zoccolillo M. Major depression during medical training (editorial). JAMA 1988;260:2560-1 1. 